in tiny localities in either or both of two quite circumscribed mountainous regions, one in northern and one in southern Norway; the nearest other representatives of these species may be as far away as Central Europe or even the Altai Mountains. This pattern is strongly suggestive of a relict population, and the botanists are unanimous that it could not be the result of a northward immigration behind the retreating ice-sheet; they maintain that there must have been ice-free refuges throughout at any rate the last glaciation, one near the Lofoten Islands and another along the north-west coast of southern Norway. Not all the geologists condemn this idea-Ives in this book maintains that parts of northern Labrador and even Baffin Land remained unglaciated-but Hoppe (pp. 321-333) denies the possibility of such refuges in Norway. To the outsider, the geological arguments against refuges seem less cogent than the botanical arguments for them. The present position is summed up on p. 231 by Faegri as follows: "The current situation is extremely unsatisfactory. The present-day distribution pattern of the Scandinavian mountain flora has been referred to ecologic and to historical reasons: Ice Age survival has been referred to marginal areas in the east, south and west of the ice sheet, and, in addition, to the coastal refugia as well as to nunataks. None of the ideas has been properly proved, none of them definitely disproved. Biologists have a problem and an attempt at an explanation. Geologists refuse to accept the explanation and cannot offer any solution to the problem".

The editors, Askell and Doris Löve, who are also contributors, deserve great credit for the production of this admirable book. The whole volume is written in English, although almost every author must have had some other language as his or her native tongue. The English. speaking peoples are continually in debt in this way to the linguistic ability and courtesy of their neighbours.

All the same, one cannot but regret that plant geographers find it necessary to use such words as 'anthropochthonous' ('spread by man' would be both English and shorter), 'anthropochorous' (presumably not a malevoice choir) and 'menotrophication'. J. S. ColmaN

\section{SCHOOL SCIENCE IN AUSTRALIA}

\section{Science for High School Students}

An integrated four-year course in physics, chemistry, biology and geology based on and covering the science syllabus approved by the New South Wales Secondary Schools Board. By the Nuclear Research Foundation School Certificate Integrated Science Textbook Group of Authors and Editors under the Chairmanship of Prof. $\mathbf{H}$. Messel. Pp. 1040. (Sydney: Published by the Nuclear Research Foundation within the University of Sydney, 1964.) 52s. sterling; 65s. Australian; 7.50 dollars.

\section{Science for High School Students}

Teachers' Manual for use in conjunction with the integrated four-year course in physics, chemistry, biology and geology based on and covering the science syllabus approved by the New South Wales Secondary Schools Board presented in the textbook. By the Nuclear Research Foundation School Certificate Integrated Science Textbook Group of Authors and Editors under the Chairmanship of Prof. H. Messel. Pp. 480. (Sydney: Published by the Nuclear Research Foundation within the University of Sydney, 1964.) 24s. sterling; $30 s$. Australian; 3.50 dollars.

THIS is a four-year course in general science for Australian high school children. The pupil's book has more than a thousand large pages, and the accompanying Teachers' Manual has nearly five hundred. The book would seem to be too heavy to be carried regularly between school and home. It is, in fact, an encyclopædia of science. General science includes mechanics, physics, inorganic, organic and applied chemistry, astronomy, geology, botany, zoology and physiology.

There is much to praise in this work if it is accepted as an encyclopædic text-book. It is the work of many practical teachers acting under an integrating and executive committee. The book was put out experimentally for pilot testing in many schools before it was printed in its present form, and even this will be subject to modification in the light of experience. This is a good point. Too many text-books are written without the necessary 'feed-back' from the teachers and students who are going to use them.

The contents of the book are related to the flora, fauna, geology, life and industries of Australasia. The language and style are appropriate, spirited and immediately attractive. The diagrams, of which there are many hundreds, the coloured plates, the simple experiments, are all of a high quality. There is a considerable selection of questions on the contents of each chapter, and most of these are framed to encourage the pupil to apply what he has learnt to problems which will lead to a further understanding of the world around him. The Teachers' Manual gives the answers, suggestions concerning the techniques of experiments, further reading for all the topics, suitable films and other visual aids. The pupil's book terminates with a comprehensive set of tables which in itself is a mine of factual information. As a volume which sets forth facts, applications and demonstrations, often miscalled experiments, of the physical and biological sciences, it must rate very highly. The amount of information it contains is quite staggering, and it is difficult to believe that even an intelligent pupil can accomplish all this work in four years, particularly as science appears to be a compulsory subject in Australian schools.

Although the book could not be of general use in Britain because of its indigenous nature, it would only be a most sophisticated teacher of general science who could not learn something from it. It makes an honest attempt to see a large field, to delay narrow specialization, to relate together the subjects of science, and the whole to life and the world around us. Our education at a higher level has suffered because of the science teacher who knows no physics or no biology, the English teacher bedevilled by a few set books and the modern language teacher who professes only one language besides his own.

Nevertheless, against this general science teaching there remain some big question marks. If the field is so wide, are the furrows going to be deep enough? If science specialization is delayed, are Advanced Level results in the General Certificate of Education in any particular branch jeopardized as a result? With the extension of higher education a new appraisal of the whole situation of science teaching is urgently necessary with a clear statement of aims at each stage, and a continuity from primary school to secondary school to the age of sixteen, again from sixteen to eighteen, to undergraduate and other post-school courses, and even postgraduate work.

There is another point of prime importance. The presentation of such an enormous corpus of scientific fact between two covers may make one wonder whether the wood of scientific method and endeavour has been obscured by the trees of scientific detail. In the present volume the pupil has reached space travel, atomic fission and the sources of the Sun's energy, the properties of astatine, among thousands of other things, and one must admit that the selection of topics has been skilful. The logarithmic growth of scientific knowledge is adding to the burden of determining what is worth teaching and the degree of specialization which is necessary at any time. Thus, it is increasingly important that the aims, contents, methods, uses and limitations of science should be considered carefully in the whole field of education.

W. L. SUMNer 